\title{
Flow Velocity Wave Forms in the Human Fetal Ductus Arteriosus during the Normal Second Half of Pregnancy
}

\author{
KARIN VAN DER MOOREN, LEO G. BARENDREGT, AND JURIY W. WLADIMIROFF \\ Department of Obstetrics and Gynaecology [K.V.d.M., J.W.W.] and Department of Biostatistics [L.G.B.], \\ Academic Hospital Rotterdam-Dijkzigt, Erasmus University Rotterdam, Rotterdam, The Netherlands
}

\begin{abstract}
Maximum flow velocity wave forms in the ductus arteriosus were studied longitudinally in $\mathbf{4 0}$ fetuses from 18 to 38 wk of gestation at 3- to 4-wk intervals. Median maternal age was 29 y (range 18-41 y), median parity was 1 (range $0-6$ ). All flow velocity wave forms were obtained using a mechanical sector scanner with a continuous Doppler system (carrier frequency 3.5 MHz). The flow velocity parameters studied were peak-systolic, peakdiastolic, and time-averaged velocity and acceleration time. There was considerable variability in measurements between fetuses at any particular gestational age. An increase of ductal flow parameters with advancing gestational age was found. They showed no correlation with heart rate. These results suggest that the normal second half of pregnancy is characterized by a reduction in right ventricular afterload. This may be a result of decreased placental vascular resistance or increased pulmonary vascular flow. Acceleration time in ductal flow velocity wave forms was significantly higher than that observed in the pulmonary artery and ascending aorta, suggesting a lower afterload in the ductus arteriosus compared with the other two outflow tract vessels. (Pediatr Res 30: 487-490, 1991)
\end{abstract}

Abbreviations

PSI, prostaglandin synthetase inhibitors

The ductus arteriosus is a large vessel that connects the pulmonary trunk with the descending aorta during fetal life. Thus, it acts as a right to left shunt at cardiac level, diverting a considerable amount of the combined ventricular output away from the lungs. In this way the total work load on the fetal ventricles is reduced, inasmuch as a large pulmonary blood flow would represent wasted circulation (1).

Doppler echocardiographic techniques are increasingly being used to study the human fetal heart (2). Also, a technique for recording blood flow velocity wave forms in the human fetal ductus arteriosus became available (3). For a proper interpretation of Doppler data, the influence of variables such as fetal behavioral states, fetal breathing movements, and fetal heart rate should be taken into account. Recently, it was demonstrated that ductus arteriosus peak-systolic velocity is fetal behavioral state dependent, being reduced significantly during active sleep as compared with quiet sleep (4). Moreover, it has been demonstrated that ductal peak flow velocity is modulated by fetal

Received October 22, 1990; accepted June 13, 1991.

Correspondence and reprint requests: Juriy W. Wladimiroff, M.D., Ph.D. Professor of Obstetrics \& Gynaecology, Academic Hospital Rotterdam-Dijkzigt Erasmus University Rotterdam, Dr. Molewaterplein 40, 3015 GD Rotterdam, The Netherlands. breathing movements (5). There is a significant reduction in ductal peak flow velocity during inspiration as compared with expiration, and this difference in peak flow velocity increases exponentially with advancing gestational age, reflecting the developing pulmonary vascular bed (5).

To our knowledge, a detailed analysis of normal fetal ductal wave forms has never been carried out in a longitudinal setting. The objective of the present study was 2-fold: 1 ) to establish the distribution of peak-systolic, peak-diastolic, and time-averaged velocities as well as acceleration time in the fetal ductus arteriosus between 18 and 38 wk of pregnancy; and 2) to determine whether there is fetal heart rate dependency for one or more of the aforementioned parameters within the physiologic fetal heart rate range (i.e. $110-160 \mathrm{bpm}$ ) and, if so, to establish the relationship between fetal period time (the reciprocal of heart rate) and the parameter concerned.

\section{PATIENTS AND METHODS}

A total of 40 women with normal singleton pregnancies consented to participate in the study. The study protocol was approved by the Hospital Ethics Committee. Fetal ductal Doppler examinations were carried out at 3- to 4-wk intervals between 18 and 38 wk of gestation. The first examination was performed between 18 and 22 wk of gestation.

Normal pregnancy was defined by a normal fetal biparietal diameter and birth weight between the 5th and 95th percentile according to Kloosterman's tables, corrected for maternal parity and fetal sex (6). The pregnancy duration was determined from the last menstrual period and confirmed by ultrasonic measurements of the biparietal diameter between 14 and 18 wk of gestation. The median maternal age was 29 y (range 18-41 y), and the median parity was 1 (range 0-6).

A combined mechanical sector scanner and continuous Doppler system (Diasonics CV 400, Milpitas, CA) with a carrier frequency of $3.5 \mathrm{MHz}$ was used for blood flow velocity measurements in the ductus arteriosus. The sector scanner operates at power outputs less than $100 \mathrm{~mW} / \mathrm{cm}^{2}$ spatial peak/temporal average in both imaging and Doppler modes by manufacturers' specifications. Two-dimensional imaging was used to ensure the correct position of the Doppler interrogation beam both before and after each Doppler tracing was obtained. Maximum flow velocity wave forms from the ductus arteriosus were collected from the conventional short axis view. The aortic arch was differentiated from the ductus arteriosus by identification of the aortic arch vessels. The Doppler beam was positioned at the junction of ductus arteriosus with descending aorta (3), and Doppler tracings were accepted when the angle between the Doppler beam and the assumed direction of flow was $10^{\circ}$ or less. Doppler studies were performed by one examiner (K.v.d.M.). All blood flow velocity wave forms were obtained during fetal apnea and stored on videotape. From hard copies the analysis of 
four consecutive wave forms was carried out using a microcomputer (Olivetti M240, Scaramagno, Italy) linked to a graphics tablet. The following parameters were calculated: peak-systolic velocity $(\mathrm{cm} / \mathrm{s})$, acceleration time $(\mathrm{ms})$, time-averaged velocity $(\mathrm{cm} / \mathrm{s})$, peak-diastolic velocity $(\mathrm{cm} / \mathrm{s})$, and period time $(\mathrm{ms})$.

Peak velocities were measured from the zero line to the highest point of the Doppler velocity peak. Acceleration time was measured as the time between the onset of ejection and the peak of velocity. Time-averaged velocity was calculated as area-undercurve divided by period time. Peak-diastolic velocities were measured from the zero line to the maximum of the Doppler flow velocity wave form during the late diastolic phase of the cardiac cycle.

All Doppler studies were performed $2 \mathrm{~h}$ after breakfast or lunch with the patient in a semirecumbent position. The duration of a single investigation never exceeded $30 \mathrm{~min}$.

Statistical analysis included assessment of the relationship between the parameters studied and gestational age by repeated measurements analysis of variance, for which the BMDP program 5V (BMDP statistical software manual, vol. 11, 1988, University Press of California) was used. $p$ values were determined by means of the sign test. The relationship between each parameter and fetal heart rate was studied as follows. For every patient, the available data were interpolated in a linear fashion to a gestational age of $30 \mathrm{wk}$ to rule out the influence of gestational age on the parameters. For each adjusted parameter and period time, the correlation coefficient was then calculated and the corresponding $p$ value established. The lower level of statistical significance was set at 0.05 .

\section{RESULTS}

The success rate for obtaining good quality flow velocity wave forms from the ductus arteriosus was $94 \%$. In each patient it was possible to obtain at least four serial recordings during the study period. On average, five investigations were performed in each pregnancy. Serial recordings were never longer than $6 \mathrm{wk}$ apart.

The relationship between any of the flow velocity wave form parameters and gestational age was approximately linear for each patient. It also appeared that the regression lines, by which the relation between parameter and gestational age for each of the patients could be described, differed significantly from patient to patient with respect to both the intercept and the slope. Therefore, the following statistical model was adopted as the basis for the calculation of approximate $95 \%$-prediction bounds for each of the parameters, when the gestational age is known:

$$
\mathrm{y}=\mathrm{a}+\mathrm{b}(\mathrm{x}-30)+\mathrm{e}
$$

where $y$ is the parameter concerned, $x$ is gestational age (wk), a is the intercept of the regression line, $b$ is the slope of the regression line, and e is an error term.

Thus, for each of the parameters, a regression line was constructed with its 2.5 and $97.5 \%$ confidence limits. The values for $\mathrm{a}, \mathrm{b}$, and e for each flow velocity parameter as well as the $p$ values of the slopes are listed in Table 1 . There was considerable

Table 1. Absolute values and standard errors of parameters determining regression lines for ductus arteriosus flow velocity parameters with gestational age according to general formula:

\begin{tabular}{lrrrrr}
\multicolumn{6}{c}{$y=a+b(x-30)+e^{*}$} \\
\hline & \multicolumn{1}{c}{$\mathrm{a}$} & \multicolumn{1}{c}{$\mathrm{b}$} & \multicolumn{1}{c}{$\mathrm{Sa}$} & \multicolumn{1}{c}{$\mathrm{Sb}$} & \multicolumn{1}{c}{ Error } \\
\hline PSV $(\mathrm{cm} / \mathrm{s})$ & 102.9 & 3.4 & 79.4 & 0.8 & 112.8 \\
PDV $(\mathrm{cm} / \mathrm{s})$ & 11.6 & 0.6 & 3.2 & 0.01 & 2.8 \\
TAV (cm/s) & 40.4 & 1.4 & 18.4 & 0.1 & 22.8 \\
ACT (ms) & 64.8 & 1.7 & 38.8 & 0.2 & 72.3
\end{tabular}

* PSV, peak-systolic velocity; PDV, peak-diastolic velocity; TAV, time-averaged velocity; ACT, acceleration time; Sa, standard error of the intercept; Sb, standard error of the slope; $\mathrm{x}$, gestational age (wk); e, error. $p<0.0001$ for all values. variability in measurements between fetuses at any particular gestational age. The data distribution for ductal peak-systolic and peak-diastolic velocity relative to gestational age is presented in Figure 1. Period time in this study ranged from 358 to 537 $\mathrm{ms}$, corresponding to fetal heart rates of 167 to $112 \mathrm{bpm}$, respectively. Average period time showed a significant increase with advancing gestational age, the regression equation being

$$
y=371.1+1.53 x
$$

$(p<0.001)$ where $\mathrm{y}$ is average period time (ms) and $\mathrm{x}$ is gestational age (wk).

The parameters studied showed a significant increase with advancing gestational age, as shown in Table 1 . Mean values ( \pm $1 \mathrm{SD})$ at $20 \mathrm{wk}$ of gestation as compared with $38 \mathrm{wk}$ of gestation were: peak-systolic velocity, $65.6 \pm 10.9$ versus $126.3 \pm 32.1 \mathrm{~cm} /$ $\mathrm{s}$; peak-diastolic velocity, $5.4 \pm 1.4$ versus $15.4 \pm 3.4 \mathrm{~cm} / \mathrm{s}$; timeaveraged velocity, $24.8 \pm 3.9$ versus $50.1 \pm 14.5 \mathrm{~cm} / \mathrm{s}$; and acceleration time, $47.5 \pm 8.7$ versus $78.4 \pm 10.2 \mathrm{~ms}$. No correlation could be demonstrated for any parameter and period time. Ductal acceleration time was significantly higher than pulmonary acceleration time $(p<0.001)$ and ascending arotic acceleration time $(p<0.001)$.

\section{DISCUSSION}

In the human fetal heart, both right and left ventricle eject in parallel into the systemic circulation: the right ventricle into the ductus arteriosus and descending aorta, the left ventricle into the ascending aorta (7). The ductus arteriosus thus acts as a right to left shunt, reducing the work load on the fetal heart (1). As can be concluded from animal laboratory experiments, the dilatation of the ductus arteriosus in utero is maximal (8), and a widely patent ductus arteriosus appears to be essential for normal fetal development (1).

In the present study, we analyzed fetal ductal flow velocity wave forms obtained longitudinally during the second half of pregnancy. An increase with advancing gestational age was found for all flow velocity parameters concerned. The distribution of these parameters increased toward term, which is in agreement with the increasing variance of biometric parameters with advancing gestational age. Fetal heart rate showed a significant decrease toward term. All parameters were fetal heart rate independent.

The gestational age-related rise in ductal peak-systolic and time-averaged velocities is in agreement with the gestational agerelated rise in semilunar peak-systolic and time-averaged velocities that we observed in an earlier study (9). It was pointed out that this velocity rise could be explained by increasing ventricular stroke volume and output, as well as by a reduction in ventricular afterload. Right ventricular afterload is determined to a considerable part by placental vascular resistance, which shows a decrease with advancing gestational age (10). Because volume flow is equal to mean velocity times area, the observed increase in peak-systolic and time-averaged velocities in the ductus arteriosus may also reflect increased right ventricular stroke volume and output. However, other variables such as the diameter and compliance of the ductus and downstream vessels (e.g. descending aorta) may play a role in the composition of the flow velocity wave form pattern in the ductus arteriosus. In a recent study, increased umbilical-placental resistance was associated with reduced peak-systolic velocities in the ductus (11). The noninvasive nature of human fetal Doppler studies does not allow differentiation between these explanations.

Ductal peak-diastolic velocity also increased during the second half of pregnancy. Like the increase of end-diastolic velocities in umbilical artery and descending aorta toward term, this is indicative of decreasing placental vascular resistance. The observed increase of acceleration time in the ductus arteriosus with advancing gestational age favors this assumption. Also, ductal acceleration time is greater than that observed in the pulmonary 

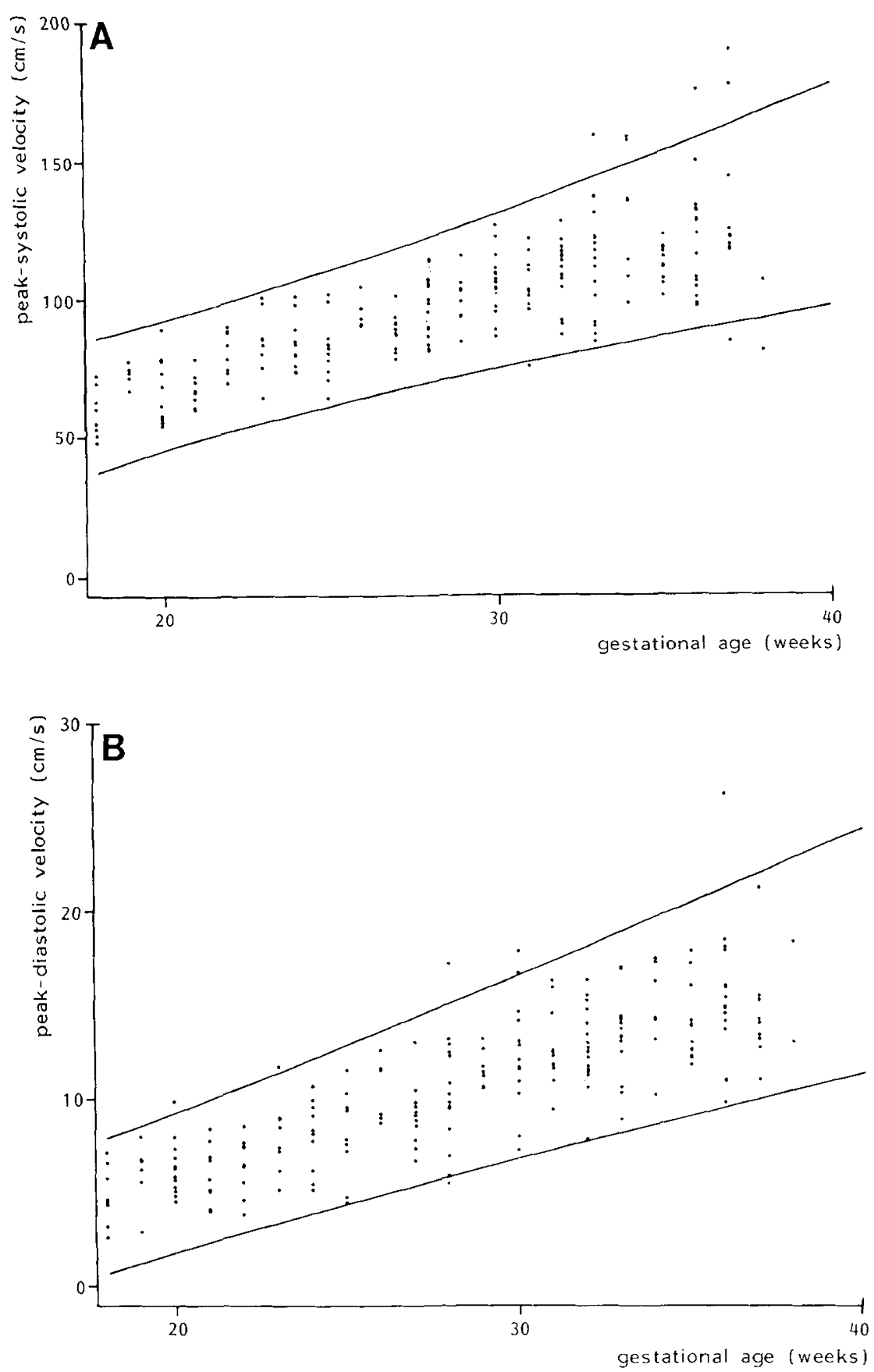

Fig. 1. Data distribution with 2.5 and $97.5 \%$ confidence limits for fetal ductal peak-systolic $(A)$ and peak-diastolic $(B)$ velocity relative to gestational age.

artery and the ascending aorta. Because Doppler echocardiographic studies have shown a close negative correlation between acceleration time and mean arterial pressure $(12,13)$, this might indicate that mean arterial pressure in the ductus arteriosus is lower than in the main pulmonary artery, suggesting a decrease in afterload from pulmonary artery to ductus arteriosus. This could imply that the pulmonary vascular bed to some extent adds to right ventricular afterload. It is not surprising that mean ductal arterial pressure seems to be lower than the mean pressure in the ascending aorta, inasmuch as the left ventricular outflow tract faces an additional afterload from cerebrum and upper extremities.

The linear increase in peak-systolic and peak-diastolic velocities in the ductus arteriosus with advancing gestational age is in agreement with the findings of Huhta et al. (3), who performed a cross-sectional study of peak-systolic and peak-diastolic veloc- ities in normal fetuses during the second half of gestation. However, our values for normal peak-systolic velocities seem to be somewhat higher, and we occasionally observed peak flow velocities of about $200 \mathrm{~cm} / \mathrm{s}$ in the last $4 \mathrm{wk}$ of gestation. It is clear from the present data that gestational age should be taken into account when using flow velocity parameters for the diagnosis of abnormal ductal velocities. To our knowledge, data concerning ductal acceleration time or time-averaged velocity have not been published elsewhere so far. The regulation of ductal patency has not been clarified in detail until now. The role of arterial $\mathrm{O}_{2}$ tension was recognized long ago, determining ductal tone by either direct action on the ductus arteriosus (1) or through influencing the production of certain intermediate substances (14). Prostaglandins are probably the most important intermediate substances, originating both from the ductal wall and from extraductal sources $(8,15)$. PSI are increasingly used in obstetric 
care, for instance for tocolysis, in which case indomethacin is the drug of choice $(16,17)$. In the human fetus, even a short course of indomethacin may be associated with a clear constrictive ductal response, characterized by a raised peak-systolic and peak-diastolic flow velocity $(3,18)$. Usually, this effect is reversible and does not seem to cause any harm to the fetus (16). Moise et al. (18) showed that during indomethacin-induced ductal constriction umbilical pulsatility index did not change. However, closure of the ductus arteriosus has been found post-mortem in a few cases after administration of indomethacin to the mother (19). There is also evidence that in utero exposure of the fetus to PSI may be one of the causes of persistent pulmonary hypertension of the newborn (20) secondary to ductal constriction. It is difficult to obtain reliable measurements of the dimensions of the human fetal ductus arteriosus by fetal echocardiography, because the ductus arteriosus can best be visualized in a short axis view and the lateral resolution of the equipment is relatively poor (16). Because animal models have demonstrated that ductal constriction correlates very well with Doppler findings (3), Doppler echocardiography may provide valuable indirect information on subtle changes in the caliber of the ductus arteriosus in utero. In case of even slight ductal constriction, both ductal peaksystolic and peak-diastolic velocity will rise significantly (3). Close Doppler echocardiographic monitoring, in particular registration of ductal peak-systolic and peak-diastolic velocity, is therefore indicated in fetuses exposed to PSI. Other Doppler echocardiographic information like the presence or absence of tricuspid regurgitation, evidence of fetal hydrops, and the amount of amniotic fluid should be looked for (16). As for Doppler monitoring, the normal values presented in this article could provide a basis for clinical use. According to our findings, the upper limit of $140 \mathrm{~cm} / \mathrm{s}$ for ductal peak flow velocity that Huhta et al. (3) proposed might be an underestimation. Many clinicians agree that indomethacin should not be used after $34 \mathrm{wk}$ of gestation $(17,18)$, by which time ductal peak flow velocities in our experience did not exceed $160 \mathrm{~cm} / \mathrm{s}$ and peak-diastolic velocity did not exceed $18 \mathrm{~cm} / \mathrm{s}$. Both parameters are fetal heart rate independent within the physiologic fetal heart rate range, as has been demonstrated for the ascending aorta and pulmonary artery (9).

It can be concluded that fetal Doppler echocardiography allows monitoring of flow velocity wave forms in the ductus arteriosus during the second half of pregnancy. Wave form analysis in this vessel suggests a reduction in right ventricular afterload during this period of gestation.

\section{REFERENCES}

1. Heymann MA, Rudolph AM 1975 Control of the ductus arteriosus. Physiol Rev 55:62-78

2. Huhta JC, Strasburger JF, Carpenter RJ, Reiter A, Abinader E 1985 Pulsed Doppler fetal echocardiography. J Clin Ultrasound 13:247-254

3. Huhta JC, Moise KJ, Fisher DJ, Sharif DS, Wasserstrum, M, Martin C 1987 Detection and quantitation of constriction of the fetal ductus arteriosus by Doppler echocardiography. Circulation 75:406-412

4. Mooren K yd, van Eyck J, Wladimiroff JW 1989 Human fetal ductal flow velocity waveforms relative to behavioral states in normal term pregnancy. Am J Obstet Gynecol 160:371-374

5. van Eyck J, Mooren K vd, Wladimiroff JW 1990 Ductus arteriosus flow velocity modulation by fetal breathing movements as a measure of fetal lung development. Am J Obstet Gynecol 163:558-566

6. Kloosterman G 1970 On intrauterine growth. Int J Gynaecol Obstet 8:895901

7. Rudolph AM, Heymann MA 1971 Fetal and neonatal circulation and respiration. Annu Rev Physiol 38:187-207

8. Friedman WJ, Printz MP, Kirkpatrick SE, Hoskins EJ 1983 The vasoactivity of the fetal lamb ductus arteriosus studied in utero. Pediatr Res 17:331-337

9. Mooren K vd, Barendregt LG, Wladimiroff JW 1991 Fetal atrioventricular and outflow tract flow velocity waveforms during normal second half of pregnancy. Am J Obstet Gynecol (in press)

10. Trudinger BJ 1987 The umbilical circulation. Semin Perinatol 11:311-321

11. Groenenberg IAL, Wladimiroff JW, Hop WCJ 1989 Fetal cardiac and peripheral arterial flow velocity wave forms in intrauterine growth retardation. Circulation 80:1711-1717

12. Kitabatake A, Inoue M, Asao M, Masuyama T, Tanouchi J, Morita T, Mishima M, Uematsu M, Shimazu T, Hori M, Abe H 1983 Noninvasive evaluation of pulmonary hypertension by a pulsed Doppler technique. Circulation 68:302-309

13. Serwer GA, Cougle AG, Eckerd JM, Armstrong BE 1986 Factors affecting use of the Doppler-determined time from flow onset to maximal pulmonary artery velocity for measurement of pulmonary artery pressure in children. Am J Cardiol 58:352-356

14. Coceani F, Olley PM, Bodach E 1975 Lamb ductus arteriosus. Effects of prostaglandin synthesis inhibitors on the muscle tone and the response to prostaglandin E2. Prostaglandins 9:299-308

15. Clyman RI 1980 Ontogeny of the ductus arteriosus response to prostaglandins and inhibitors of their synthesis. Semin Perinatol 4:115-124

16. Moise KJ, Huhta JC, Sharif DS, Ou C, Kirshon B, Wasserstrum N, Cano L 1988 Indomethacin in the treatment of premature labor. $N$ Engl $J$ Med 319:327-331.

17. Niebyl JR, Witter FR 1986 Neonatal outcome after indomethacin treatment for preterm labor. Am J Obstet Gynecol 155:747-749

18. Moise KJ, Mari G, Kirshon B, Huhta JC, Walsh SW, Cano L 1990 The effect of indomethacin on the pulsatility index of the umbilical artery in human fetuses. Am J Obstet Gynecol 162:199-202

19. Arcilla RA, Thilenius OG, Ranniger K 1969 Congestive heart failure from suspected ductal closure in utero. J Pediatr 75:74-78

20. Turner GR, Levin DL 1984 Prostaglandin synthesis inhibition in persistent pulmonary hypertension of the newborn. Clin Perinatol 11:581-589 